\title{
STRENGTH THROUGH SHARING: INTERDISCIPLINARY TEAMWORK IN PROVIDING HEALTH AND SOCIAL SERVICES TO NORTHERN NATIVE COMMUNITIES
}

\author{
MARGARET BOONE, \\ Lakehead University \\ BRUCE MINORE, \\ Centre for Rural and Northern Health Research \\ MAE KATT, \\ Bear Island Nation \\ Medical Service Branch \\ Health Canada \\ and \\ PEGGY KINCH \\ Nishnawbe-Aski Nation
}

\begin{abstract}
The delivery of health and social services in Canada's northern First Nations is undermined by the fact that professionals from outside and paraprofessionals from the communities often fail to respect one another's capabilities or to understand one another's roles and, consequently, do not work well together. This paper explores the personal, professional, and situational causes, using examples of mental health care in the Sioux Lookout Zone of northwestern Ontario. Arguing that an interdisciplinary team approach is the ideal and, perhaps, the only real way in which essential services can be delivered, the authors suggest ways to achieve more effective collaboration.
\end{abstract}

\section{INTRODUCTION}

"In a crisis we know everything, but when things are going fine we don't seem to know much." That, according to the Community Health Representative (CHR) from one Nishnawbe-Aski First Nation, describes the working relations between professionals attracted to her community from outside, and paraprofessionals, like herself, from the community. She alludes here to two of the fundamental challenges that still face health and social service providers working together in northern native communities: respecting one another's capabilities and understanding one another's roles. Even though the "team" concept and transcultural preparation are commonly included in their education, putting these ideas

The authors wish to acknowledge the financial support provided for their research by the Ontario Ministry of Health. The resulu and conclusions are the suthors' alone, however, no official endorsement by the Ministry is intended or should be inferred. 
into practice, it seems, proves difficult. Moreover, they work in a situation where the concepts are supported in principle, but not necessarily implemented.

Our purpose in this article is to help those interested in working in such settings to deal with these challenges. Since there are few service providers in most northern First Nations communities, usually only one or two from any discipline, the best services are offered when these individuals share the strengths that come from their different backgrounds and training. The authors believe that this type of interdisciplinary teamwork is the preferred and, indeed, probably the only viable way of ensuring that the services provided are both appropriate and adequate for the communities' needs. In the following pages we use experiences in one part of northern Ontario, the Sioux Lookout Zone,' to examine the particular needs of the many aboriginal Canadians living in similar situations, and to consider the unique interdisciplinary teams that are possible in their communities. We also identify some factors-personal or professional, and situational-that stand in the way of mutual respect and understanding and, hence, limit cooperation. Finally, we weigh the benefits of effective collaboration against the consequences of noncollaboration. While most references are to the social welfare and health sectors, the education and justice sectors are also part of the human services system being discussed.

Our observations are based on a series of studies: (a) the Nishnawbe-Aski Nation's 1990 community consultation on youth suicide; (b) the Nishnawbe-Aski Nation's 1992 Aboriginal Health Policy Consultation with residents and aboriginal agencies and organizations; (c) a national survey on the preparation for northern health practice conducted by the present authors in 1992; (d) in-depth interviews completed in the spring of 1993 with 48 current and former native health paraprofessionals, also conducted by the present authors; (e) a 1994 case study of an interdisciplinary team of health and social service providers dealing with a critical incident in one remote Cree community: and (f) a series of interviews with members of an interdisciplinary team in another community which, in 1995. suffered the loss of four youth to suicide. Our focus in this article is on interdisciplinary teamwork; however, we chose to use the management of instances of suicidal behaviour to illustrate key points because we have addressed the issue extensively in our own research. Focusing upon other social problems such as spousal violence or substance abuse would be equally instructive,

\section{MULTIDISCIPLINARY AND INTERDISCIPLINARY TEAMS}

In reference to health and social service teams, the words "multidisciplinary" and "interdisciplinary" are commonly used and commonly misused terms. Yet the distinctions between a multidisciplinary team and an interdisciplinary team are fundamental and of great importance. In a word, the multidisciplinary team may be thought of as "constrained." Often the members of the team come together for specific tasks, bringing their professional knowledge and working within the parameters of that knowledge, under the leadership of an individual who assumes the role by virtue of his or her profession (i.e., because he or she is the social worker on the team, or the physician). The approach structures the team according to what is generally termed (even in social services) "the medical model," reflecting its roots in health services. In problem solving, emphasis is given to 
combining the professional knowledge brought to the table, rather than looking for answers in new knowledge created by the synergy of professional interaction. "Indeed, multidisciplinary teams are often formed to deal with difficult problems that are ordinarily within the scope of a primary profession yet have aspects that require the consideration of other professionals" (Fatout \& Rose, 1995, p. 54). By way of comparison, the interdisciplinary team may be seen as "unconstrained"; working together to address various issues over an extended period, the members participate and/or take leadership responsibilities because of their particular expertise as individuals or their relationships with clients, not simply because of the positions they hold. "In contrast to multidisciplinary teamwork, interdisciplinary teamwork is characterized by shared purpose, creative problem solving, and synergy in which combined activities result in a product that is greater than the individual components" (Fatout \& Rose, 1995, p. 51). Inevitably some changes in the team's composition will occur, as people take new jobs or different expertise is required. However, because they tend to work together for longer periods and to cross role boundaries, the interdisciplinary approach fosters the building of an esprit de corps among team members and diminishes the guarding of professional turf:

The emphasis on individual competence rather than professional roles encourages team members to adopt "more flexible and less stereotyped approaches to services" (Baldwin, 1993, p. 152). It also permits the inclusion of a broader base of expertise. For example, in the case of First Nation communities in the Sioux Lookout Zone there are a number of categories of paraprofessional workers (local residents recruited and trained to do specific tasks) available in both the health and social service sector. The former include: community health representatives (CHRs), mental health workers (MHWs), grief counsellors, and National Native Alcohol and Drug Abuse Program (NNADAP) workers. The latter would include: the band family service workers, crisis team leaders, and Tikinagan (child welfare) workers. As well traditional healers, elders, band councillors (elected), and the police or band constables are among the wealth of human resources from which First Nation communities draw.

Interdisciplinary teams are inherently inclusive in nature, wherever found. But in Canada's First Nation communities the form of such teams can be utterly unique for several reasons. One, of course, is the range of workers available, each with widely disparate preparation for their roles. A second is the small number of individuals in any one category who are present in a single community. Third, is the fact that the communities accept both professionals and paraprofessionals, and expect them to work cooperatively with one another. Nurses taking jobs in single industry towns in Canada's mid-north would rarely find themselves collaborating with the police-beyond their mutual, officially set obligations-in quite the way they would work with the band constables, if they were to go to northern native communities.

Despite the fact that cooperative teamwork, whether interdisciplinary or multidisciplinary in character, is widely accepted as ideal by human service providers, its implementation in practice is often difficult. There are many reasons why this is the case. In the following section we deal with several personal, professional and situational factors that work against easy and effective collabora- 
tion, especially as they apply in northern native communities. These are not the only factors impeding cooperative efforts, but the authors believe they are all factors which practitioners, themselves, can address.

\section{RESPECTING ONE ANOTHER'S CAPABILITIES AND UNDERSTANDING ONE ANOTHER'S ROLES}

Personal beliefs about one's own profession-usually its superiority-are one of the most frequently noted obstacles to people from different disciplines working well together. Frankel, Speechley, and Wade (1996) examined the structural reasons why, for example, nurses, occupational therapists, physicians, physiotherapists, and others have difficulty functioning together as teams. They note, in particular, a habit which signifies the quite common, thinly veiled hostility: "Health care professionals tend to make prejudiced and disparaging comments about other professionals purely on the basis of their degrees and specialities" (p. 56). The authors suggest that such a belief system takes hold while people are still students. Once established these views become the root cause of intense professional turf wars. It is interesting to note that a group of consumers, policy makers, professionals, and researchers from across Canada echoed this sentiment at a national conference on rural and northern health care delivery held in Thunder Bay. After three days spent surveying the increasing dernands and declining resources in the system, there emerged a collective plea for professionals to stop the show of "arrogance or possessiveness" reflected in their battles over turf. "What is it about the educational process that leads to this attitude?" someone wondered, affirming the view that these beliefs take hold early in a person's career (Pallen \& Boone, 1995, p. 639).

Nevertheless, these are attitudes which are held by individuals; as such, they operate as a personal barrier to effective collaboration. Of course, attitudes-and the behaviour resulting from them-can change. And even if the underlying attitudes remain, the way in which they are expressed can be altered. "One does not expect members of the helping professions to abandon concerns about turf. However, a greater willingness to be less defensive within the team itself is likely to improve the functioning of the team (Fatout \& Rose, 1995, p. 53).

The flip side of such discipline-centric attitudes is a lack of understanding about other disciplines. For example, Gregory (1992) found nurses working in northern native communities were frequently ignorant of the roles and responsibilities of the paraprofessionals who worked alongside them every day. This was borne out in interviews with northwestern Ontario paraprofessionals, conducted by the present authors. Complaints, such as the following by a CHR, were common: "I am unable to complete my tasks [because the nurses] expect me to translate all the time" (Kinch, Katt, Boone \& Minore, 1994, p. 95). A lack of understanding, leading to inappropriate demands, does not necessarily connote a lack of personal or professional respect. Nonetheless, that is how it tends to be interpreted. This naturally introduces a tension into team relations that reduces the likelihood of even minimal cooperation, let alone effective collaboration.

The lack of knowledge about the roles of other disciplines, combined with a conviction that their own roles are bound by practice and/or convention, means 
service providers function to a remarkable extent in professional isolation. This may be understandable; Hertzberg (1993) notes that most disciplines "have little or no background or education in interdisciplinary team functioning and may tend to favour discipline specific priorities over team goals" (p. 47). Nonetheless, it is not acceptable, especially not in a work environment where there are many other restrictions in place. Here, again, gaps in knowledge exist at a personal level, and can be addressed by the individual practitioner. DuBois, Nugent, and Broder (1991), in an article on extending psychiatric services to underserviced areas, argue that members of a team simply must recognize that individuals from other disciplines have "equal but different expertise" (p. 459), and develop confidence in their co-workers' knowledge, skills, and judgement.

\section{SERVICE PROVIDERS AND THEIR COMMUNITY: THE VITAL LINK}

Support and acceptance by the community is one factor which falls within the overlap of personal or professional and situational barriers to collaborative practice. Concern about the team members' connectedness to the community they serve has several bases. One is the issue, mentioned above, of meeting the communities' expectations for cooperation among service providers. This was clearly expressed during the community consultation on youth suicides in the First Nations of northwestern Ontario: "Community resource people need to form better networks, and meet together to share concerns and issues" (Nishnawbe-Aski Nation [NAN], 1990, p. 15). As well, there is the matter of their professional relationship with the community. O'Neil (1989) notes a tendency on the part of some individuals to remain aloof in their interactions, seemingly believing, albeit falsely, that they must do so to maintain control. Such a stance is the exact opposite to the communities' views expressed in the NAN suicide consultation. "The workers' job is to make sure that all community members know that they are there to help, and to encourage people to work together to prevent hopelessness and suicide" (Minore, Boone, Katt, \& Kinch, 1991, p. 13). The reader can well imagine the misread cues that result when service providers attempt to control by maintaining social distance, while, at the same time, community members expect they will be consulted about the delivery of services.

There is also the issue of service providers consulting the community leadership in the appropriate way; not just as a political necessity or mere courtesy, but in a manner that permits, and even requires the leader' active involvement in service provision. Many, if not most First Nations in the Sioux Lookout Zone have organized committees to give input on the delivery of human services. Together with the band counsellors, the members of these committees constitute a source of local expertise which all front-line workers should recognize and exploit-in the best sense of the word-for the communities' advantage.

For those from outside the community, connectedness has a personal dimension too. In the smaller isolated native communities of the north, it is difficult to separate one's personal life from one's professional life and one's presence as a community member from one's presence as a member of the health or social services system. Goodwill (1984) reports that even nurses who happened to be of 
aboriginal ancestry themselves, felt isolated and lonely when they went to work in such communities. While professionals identify social isolation and lack of support systems as personal issues, these are problems which can be attributed to the lack of acceptance by the community. This duality was raised by Wodarski (1983), who cautioned mental health social workers going to practice in rural communities that they "are often not only viewed as outsiders, but also as a symbol of mass society and, as such, are not readily welcome into the community and must work at being accepted" (p. 7). While individuals may feel they are not accepted by the community, this may reflect their own lack of acceptance of the people or the place. To be accepted, the outsider must recognize that they are part of the community while they reside there. Cultural differences notwithstanding, they need not fear being presumptuous in joining the community. After all, steadfastly maintaining social distance is far more damaging to relations than the occasional overstepping of social boundaries.

Paraprofessionals from the communities in northwestern Ontario have a different problem. Although acceptance is not guaranteed, those we interviewed report having connections with virtually everyone in their communities; relationships which either did not change or improved when they adopted their paraprofessional roles. But even these are always potentially at risk. As one man noted, although he had experienced no changes as yet, "if a crisis arises I don't really know what effect it would have on my relationship with the community" (Kinch et al., 1994, p. 96).

Teamwork may be overshadowed by the fact that everyone in the community is known to the service providers, and in the case of the paraprofessional may even be related to them. The issue of confidentiality then becomes a major constraint on their personal and professional lives. A former CHR reports:

I more or less kept to myself. I think that's why I got burned out fast. The reason why I didn't talk to my family or friends in the community was confidentiality. I didn't know how much I should be saying, so I didn't say anything at all (Kinch et al., 1994, p. 96).

This person failed to understand the need to draw a distinction between sharing information informally, outside of the context of helping the client, and sharing it appropriately in order to help the client. In fact, workers should feel comfortable with exchanges among the members of the team as required for effective case management. This can be achieved if clients give informed consent, permitting workers to consult across discipline boundaries. Particulars remain confidential to the team, however, and personal oaths of confidentiality are still honoured.

\section{FEATURES OF THE WORK ENVIRONMENT: COMMUNITIES AS CONTEXT}

Service providers' work lives and, ultimately, their functioning as a team are shaped by more than their own knowledge and attitudes. They are also determined by the nature of the communities in which the service delivery systems function. In the following section we illustrate the effects a given work environment can have on members of the team. We use the Sioux Lookout Zone experience as an 
example, but similar situations will be encountered in native communities throughout northern Canada.

The 28 Nishnawbe-Aski First Nations in the Sioux Lookout Zone are scattered over a vast subarctic region in Ontario that stretches north from the 50 th to approximately the 58 th parallel, and west from the Hudson's Bay coast to the Manitoba border. The area is sparsely populated; by latest count (1994) only 13,389 Cree and Ojibway people lived in the communities; as few as 30 people in the smallest, and as many as 1,600 in the largest. The demographic profile shows the population is youthful- $67 \%$ are less than 30 years of age-that the mean level of education is less than grade nine, that unemployment rates are as high as $95 \%$ of those able to work, and that most people survive on social assistance benefits. They live in a paradoxical world where the staples of a hunting people's diet are three-dollar-a-litre milk and frozen pizza flown from the south, where they can watch 24-hour-a-day television via satellite in houses that do not have running water or indoor plumbing, and where diagnostic equipment in the nursing station sits idle in need of minor repairs because nobody in the community has been trained to fix it. It is also a complex world: Communities differ markedly from one another. Some are traditional and resistant to change while others embrace new developments. Some witness continuous internal political friction, while others are stable and well managed. Some suffer from rampant alcohol and drug abuse, while others are stringently "dry" communities. Some are highly religious, others not.

Outsiders frequently fail to recognize these differences, tending instead to assume a homogeneity in Nishnawbek life that does not exist. When outsiders consider the social conditions, they often overlook the forces of cohesion while paying attention to the disintegrative pressures. This creates a practice orientation among service providers that focuses on problems rather than strengths.

The nature of the health and social service system in the region is dictated not only by the small size of the Nishnawbe-Aski First Nations, but by their relative isolation. Four of every five communities are accessible only by airplane (the most remote by float plane which means transportation links are cut for a month during both fall "freeze up" and spring "break up"). A low population density. compounded by isolation, has resulted in a human services system where physical and human resources are scarce-not per capita but due to geographical dispersion. Moreover, these factors have led to a regional rather than community-centred system of services. No one place is large enough to sustain a comprehensive network of services. Consequently, service providers tend to orient outward. having allegiances to a regional reference group rather than seeing persons in the community as peers and finding support among them.

The nature of the health care system can be used to illustrate why this orientation to external expertise occurs. The reader should bear in mind, however, that parallel situations also exist within the social welfare system, the educational system, and the justice system. In larger places primary health care is provided by resident nurses and paraprofessionals. Their services are augmented by regular visits of general physicians from the zone bospital and less frequent visits by other health providers such as dentists, psychiatrists, physiotherapists, and dietitians. Smaller communities usually have only a community health representative (CHR), who works alone with the support of a nurse visiting weekly. In addition, long- 
distance telephone consultations are commonplace. In other words, communitybased service providers routinely work with outside professionals. In the event of a crisis, the client is flown out, either to the Sioux Lookout Zone Hospital or another facility located in the larger urban centres of Ontario's midnorth. The secondary or tertiary care received in such institutions tends to be discipline specific (within the domain of psychiatry, for example). When the client returns home, his or her care plan-if there is one-usually involves a single worker within the community, rather than incorporating a broader team approach. The combined effect of telecommunication-linked or fly-in expertise on one hand, and fly-out medical evacuation of clients on the other, works against building integrated teams within communities.

The result is a "segmented" human service system. For purposes of clarity diagram 1 was drawn to graphically depict how people function within such a system. First, note that the entire human service system is clearly divided into

\section{DIAGRAM 1}

Segmented Human Service System

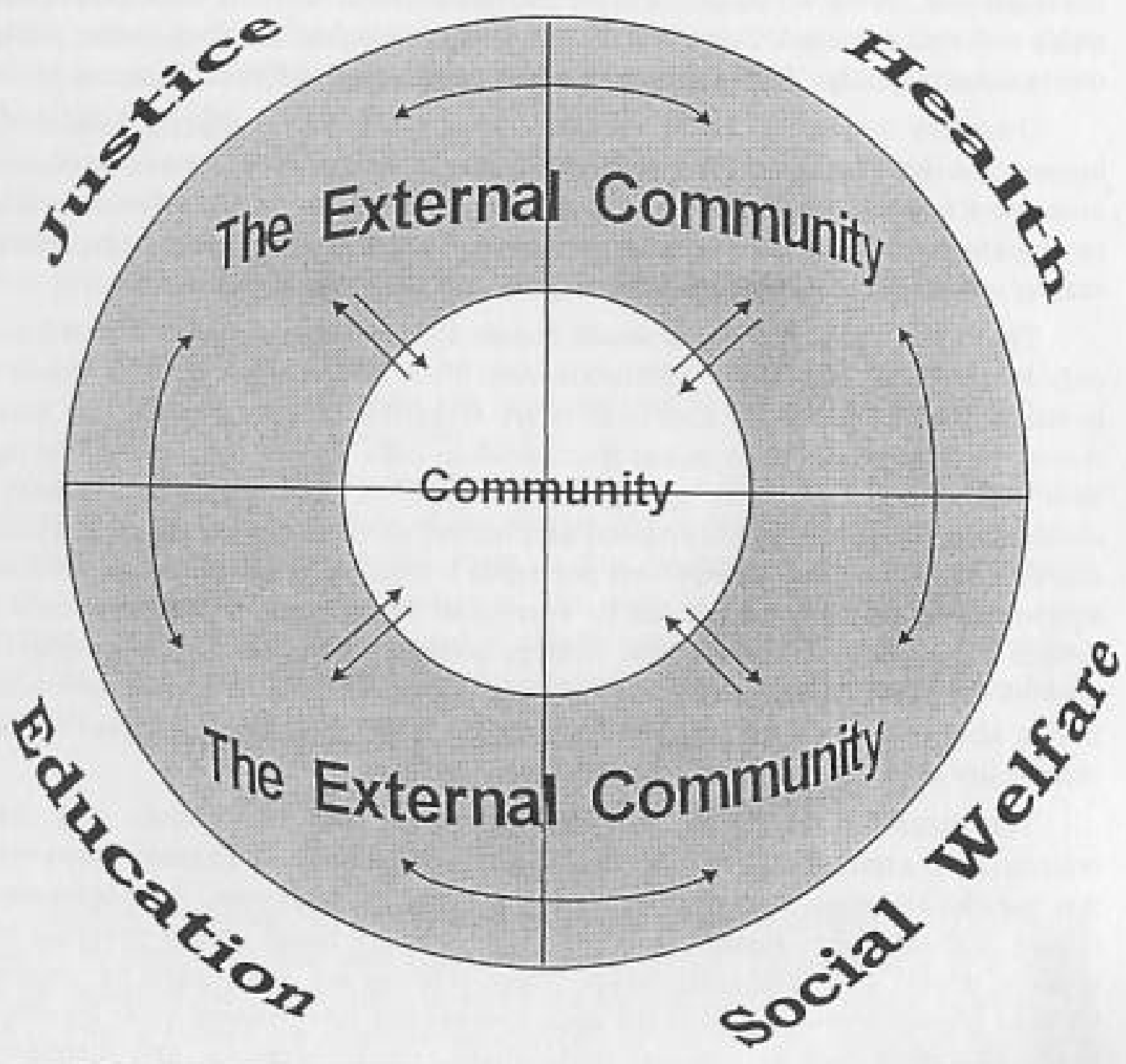


sectors-social welfare, health, education, and justice-and that these divisions exist within and externally to the community. In this diagram, services at the community level are surrounded by external programs and support systems that provide resources to them. The arrows indicate the direction of most communication that occurs within the system.

Thinking back to the distinction between "multidisciplinary" and "interdisciplinary" teams, it is evident that the situation depicted in the diagram is more the former than the latter. As indicated in the community circle, individuals from different fields work side by side, but operate within the bounds of their own disciplines (characteristic of the multidisciplinary approach). This occurs even when they are dealing with very serious occurrences in very small, geographically remote places where the number of service providers are limited. In what follows we will consider the cases of "Mathew" and Tony Fireman.

\section{CASE EXAMPLES: SHORTCOMINGS OF THE MULTIDISCIPLINARY APPROACH}

In order to gain an understanding of the functioning of human service teams in crisis situations, the authors arranged to interview all front-line workers in an isolated Cree community. When discussing a particular case, a series of suicide attempts by 17-year-old "Mathew," it became evident that everyone had a clear sense of their own roles in the situation and a conviction that they had boundaries within which to work. They expressed respect for the knowledge possessed by those from other disciplines, but at the same time demonstrated that they did not completely understand what these people could and should do in the event of a crisis. As a result, they tended to rationalize their own behaviours in relation to limits which they believed their discipline or circumstances had imposed on them. For example:

The nurse explained that when she was called to the house: "I certainly didn't take charge because to me [the situation] had already been taken charge of "by the CHR "because she's kind of like a family member to those people." The NNADAP worker also put his involvement in the incident into a broader role context. "Usually what happens is that when the person attempting suicide is drunk the first person [called] is the police, and when they (the victims) are not drunk it's usually me" (Katt, Kinch, Boone \& Minore, in press).

The people quoted above used aspects of the situation to justify restricting their involvement. Although their statements imply a respect for others' knowledge, they also show an unwarranted willingness to let others deal with a difficult situation.

In diagram 1, the shaded area surrounding the community centre represents the supporting system of programs outside the community which sustain the community services. Professionals in the community turn to these programs for support, but they also report (and are accountable) to these programs. Concerns about confidentiality reinforce the tendency toward external rather than internal contacts. Hence the arrows indicate an outwardly directed communications path from the community workers, but one that remains within a given service sector. In the case of Mathew, team members report finding their support outside the community, For example, the nurse indicated that "I would talk to my ZNO (zone nursing officer) if 1 had to talk to someone in a big hurry." This two-way 
communication between professional colleagues results both in the funnelling of information or concerns outward, and the directing of external expert knowledge to specific individuals or discipline groups in the community, rather than to the human service team on site in the community.

The boundary lines between sectors in the outer circle on diagram 1 reflect the fact that the sectors have different mandates, function under different sets of enabling legislation (both federal and provincial), and have different sources of funding (Helin, 1993). As the arrows crossing sectoral boundaries indicate, there is interaction between programs or agencies in different sectors. Many would argue that the extent of these exchanges is insufficient, given the overlapping nature of issues they face in common. Nonetheless, lines of communication are in place which facilitate intersectoral, interdisciplinary teamwork at the regional level.

It must be pointed out, however, that all too often facts vital to clients' care are not communicated to anyone in the community. In 1993, the story of Tony Fireman of Altawapiskat, Ontario was headline news. This 18 year old, "high" from sniffing gasoline, shot himself to death in front of his mother and two

\section{DIAGRAM 2}

Integrated Human Service System

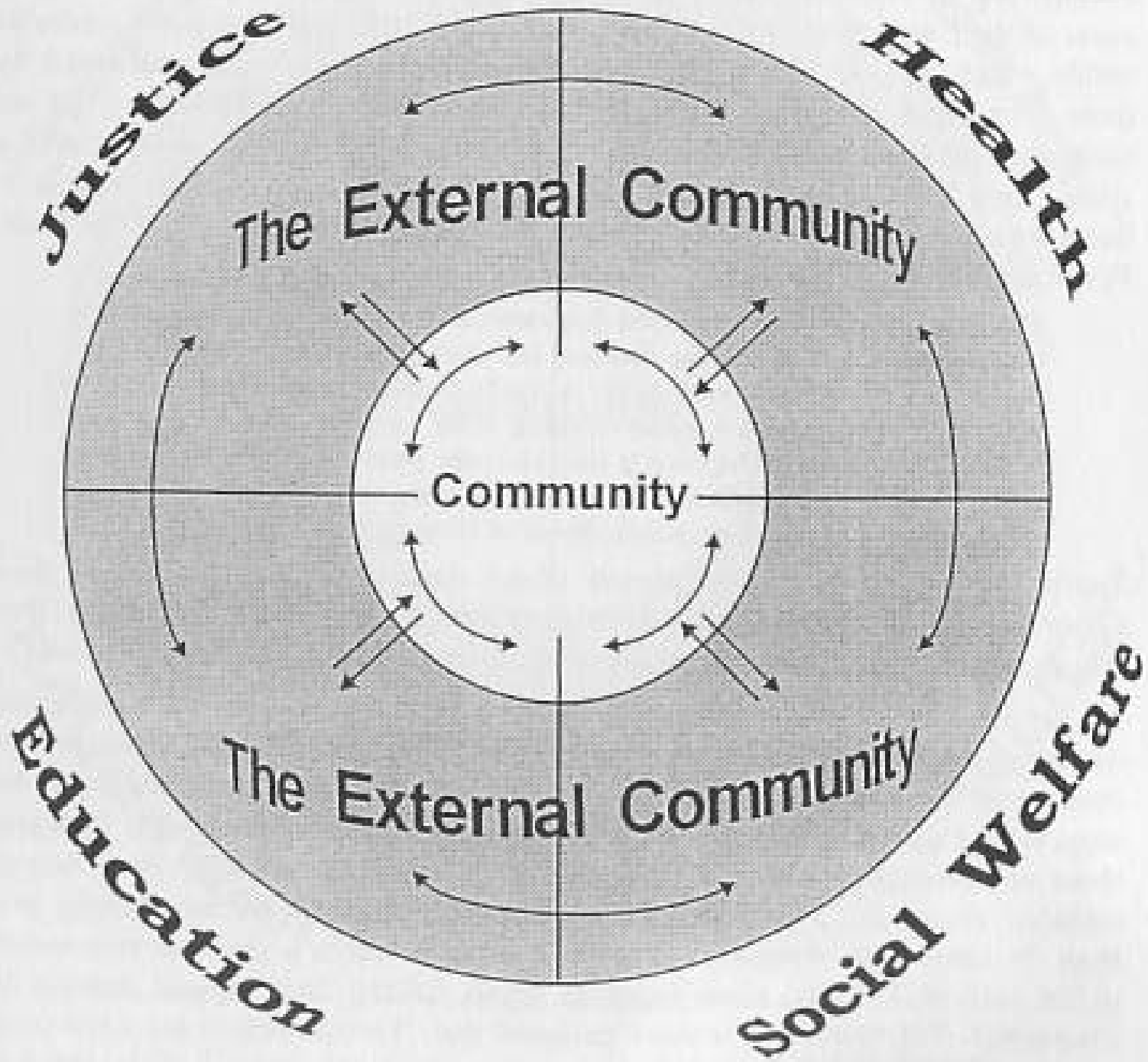


police officers. An ensuing investigation revealed that, although Tony had received care at an out-of-province treatment centre in the previous year, no aftercare or discharge planning was done, nor was anyone in Attawapiskat contacted and told how to support the teenager when he returned to the community.

\section{AN ALTERNATIVE: THE INTEGRATED HUMAN SERVICES DELIVERY MODEL}

Diagram 2 illustrates our ideal: an "integrated" human service delivery model for First Nation communities. When compared with the first diagram, although the outer boundaries remain the same, the degree of segmentation and lines of communication are significantly different. The lines connoting the different service sectors cross into the community circle because each front-line worker has a defined, discipline-based body of knowledge on which they draw. But they do not cut right across the circle. In other words they do not represent professional boundaries that lock others out. Rather, the community circle remains open, signifying the nature of the dialogue possible among those responsible for social welfare, health, education, and justice, In a word, this is the "interdisciplinary" approach. In this diagram, as in the first, the direction of communications is indicated by arrows. While dialogue within the community is added here, the outward communication remains the same. The latter is still important: Given the dispersed nature of the population and scarcity of human resources at the community level, it is essential to maintain consultation and program supports at a regional level. Of course the divisions between the sectors continue in place; but, again, protocols facilitate the occurrence of intersectoral contacts.

The integrated model permits the adoption of approaches that incorporate community strengths. For example, the lack of mental health services in the region is well recognized. The need is equally evident, witness the incidence of youth suicides. An amalgam of providers struggle to respond to mental health issues. The current approaches include NODIN counselling services, centred in Sioux Lookout, but complemented with the rotation of psychiatrists who visit from the University of Toronto and with mental health workers stationed in many northern communities. Still the need far overwhelms the supply of services. It is just this sort of underserved situation which invites consideration of the model which DuBois, Nugent, and Broder (1991) propose, wherein psychiatric and psychological services for children are offered through a network of community-based providers. One key to achieving this "multiplier effect" is the maintenance of links among providers in the community and between them and other outside professionals.

\section{CONCLUSIONS}

By now some of the consequences of noncollaboration will be apparent. On one hand, situations like Mathew's case are made worse when members of the community's human service team fail to communicate with one another, are unaware of what others could or should do, and are unwilling to step beyond selfdefined role boundaries, even in a crisis. On the other hand, the tragedy of Tony Fireman's death reveals the consequences of inadequate communication between 
front-line workers in a community and the larger external system which is supposed to support them in their work. The gaps created and barriers raised in either situation often prove lethal. In addition, young people and others who are well aware of the frictions that exist can and do use them to manipulate the system for short-term advantages.

The benefits of collaboration should be equally clear, both for the consumers (clients and communities) and the service providers. Clients enjoy better, coordinated services, early interventions if necessary, and appropriate prevention programs. The communities are assured of a cohesive net of services and, through external links, the best assistance available. For their part, the service providers gain, not only by extending their knowledge, but by having support in often stressful situations.

In this article we argue that the interdisciplinary team approach is the ideal and perhaps the only real way in which essential services can be delivered in Canada's northern native communities. Interdisciplinary teams can be inclusive, they can be responsive, and they can be flexible. For those intending to go north to practice, we offer the following points to remember:

- Understand the roles of all players on the team. Interdisciplinary teams in the north are unique and include both professionals and paraprofessionals drawn from the social welfare, health, education, and justice sectors.

- Respect the knowledge and capabilities of all team members. In doing so, use your own discipline-based knowledge creatively, adapting and adopting the "equal but different" knowledge that other disciplines bring to situations.

- Recognize that you are part of the community while working and living there. Altempting to maintain social distance-either, at best, for fear of overstepping social boundaries, or at worst, to exercise control-irreparably damages relations with the community.

- Involve the community generally, and the leaders particularly, in the development and delivery of services. The collective knowledge of the community is one of the teams' most valuable resources.

- Understand that client confidentiality can be maintained within the team without violating personal or professional codes if informed consent is obtained from the clients. This approach enables team collaboration and ensures good case management.

- Maintain channels of communication between the human service sectors within and outside the community. This enhances the possibility that clients will receive "seamless" services from the system.

- Understand the specific human service system in which you function. including any overlaps and constraints. This knowledge will help guide you in providing services to clients.

More, perhaps, than at any time in the past, native Canadians are witnessing rapid changes in the way in which human services are provided in their communities. Approaches change, responsibilities shift, budgets are cut, but one need remnins: those who provide services must learn about one another's knowledge 
and skills-out of that will come respect for their capabilities and strength through sharing.

\section{NOTES}

1. The Sioux Lookout Zone is an organizational division of the Medical Services Branch of Health Canada.

\section{RÉSUMÉ}

La mise à disposition des services sociaux et médicaux parmi les Premières Nations du nord du Canada est sapée par le fait que des professionnels venant de l'extérieur et des paraprofessionnels de communautés mẻmes n'arrivent pas à respecter les aptitudes ni à comprendre les rôles les uns des autres et, par conséquent, ne coopèrent pas bien. Cet article examine les causes personnelles, professionnelles et situationnelles de ce manque de compréhension, en tirant des exemples des services psychiatriques dans la Zone de Sioux Lookout, au nord-ouest de l'Ontario. En soutenant qu'une approche interdisciplinaire, entreprise dans un esprit d'équipe, est la façon iđéale, voire unique, d'offrir des soins de base, les auteurs suggèrent des moyens d'atteindre une collaboration plus efficace.

\section{REFERENCES}

Baldwin, S. (1993). The myth of communiry care: An alternative neighbourhood model of care, London: Chapman \& Hall.

DuBois, J., Nugent, K., \& Broder, E. (1991). Psychiatric consultation with children in underserviced areas: Lessons from experiences in northern Ontario, Canadian Jounial of Psychiatn, 36, 456-461.

Fatout, M., \& Rose, S. (1995). Task groups in the social services. Thousand Oaks: Sage,

Frankel, B., Speechley, M., \& Wade, T. (1996). The sociology of health and health care: A Canadian perspective. Toronto: Copp Clark.

Goodwill, J. (1984), Barriers to employment and retention of native nurses. Ottawa: Indian and Inuit Nurses of Canada.

Gregory, D. (1992). Nursing practice in native communities, In A. Baumgart \& J. Larsen (Eds.), Canadian nursing faces the future (pp, 181-198). St. Louis: Mosby Year Book.

Helim, S. (1993). Beyond the caregivers: Health and social services policy for the 1990s. In Royal Commission on Aboriginal Peoples, The path to healing (pp, 158-170). Ottawa: Government of Canada.

Hertzberg, D. (1993). The interdisciplinary team: The experience in the Armenian pediatric rehabilitation program. Holistic Nursing Practice, 7, 42-48.

Katt, M., Kinch, P., Boone, M., \& Minore, B. (in press). Coping with northern aboriginal youth suicide, In A. Leenaars, S. Wenckstern, L. Sakinofsky, M. Kral, R. Dyck, \& R. Bland (Eds.), Suicide in Canada. Toronto: University of Toronto Press.

Kinch, P., Katt, M., Boone, M., \& Minore, B. (1994). On being everything and nothing: The retention of native health workers in northern communities. In G. Petursdottir, S. Sigurdsson, M. Karisson, \& J. Axelson (Eds.), Circumpolar health 93: Proceedings of the 9th international congress on circumpolar health, Arctic Medical Research, 53 (Suppl. 2), $92-97$.

Minore, B., Boone, M., Katt, M., \& Kinch, P. (1991). Looking in, looking out: Coping with adolescent suicide in the Cree and Ojibway communities of northern Ontario. Canadian Journal of Native Studies, XI, 1-24. 
Nishnawbe-Aski Nation, (1990). Community response to suicide: A model for caring and sharing . ... for our young. Thunder Bay, ON: Author.

Nishnawbe-Aski Nation. (1992). For a healthier future: The aboriginal health consultation final report. Thunder Bay, ON: Author.

O'Neil, J. (1989). The politics of health in the fourth world: A northern Canadian example. In K. Coates \& W. Morrison (Eds.), Interpreting Canada's north: Selected readings (pp. 279-298). Toronto: Copp, Clark, Pittman.

Pallen, D., \& Boone, M. (1995). Translating issues into action: A synopsis of group discussions. In B. Minore \& C. Hartviksen (Eds.), Redressing the imbalance: Health human resources in rural and nonhem communities, conference proceedings (pp. 633641). Thunder Bay, ON: Lakehead University, Centre for Northern Studies, Occasional Paper \#16.

Wodarski, J. (1983). Rural mental health practice. Baltimore, MD: University Park Press. 